\title{
Muscle and Fasciae of the Thorax
}

National Cancer Institute

\section{Source}

National Cancer Institute. Muscle and Fasciae of the Thorax. NCI Thesaurus. Code C33145.

Any of the skeletal muscles and/or fibrous tissue located in the thorax. 